\title{
REPAIR OF CRITICAL-SIZED BONE DEFECTS WITH ANTI-MIR-31-EXPRESSING BONE MARROW STROMAL STEM CELLS AND POLY(GLYCEROL SEBACATE) SCAFFOLDS
}

\author{
Yuan Deng ${ }^{1, \S}$, Xiaoping Bi ${ }^{1, \S}$, Huifang Zhou ${ }^{1}$, Zhengwei You ${ }^{2}$, Yadong Wang ${ }^{3}$, Ping $\mathrm{Gu}^{1}$ and Xianqun Fan ${ }^{1, *}$ \\ ${ }^{1}$ Department of Ophthalmology, Ninth People’s Hospital, Shanghai Jiao Tong University School of Medicine, \\ Shanghai, China \\ ${ }^{2}$ State Key Laboratory for Modification of Chemical Fibers and Polymer Materials, \\ College of Materials Science and Engineering, Donghua University, Shanghai, China \\ ${ }^{3}$ Department of Bioengineering and the McGowan Institute, University of Pittsburgh, Pittsburgh, PA, USA
}

$\S$ These authors contributed equally.

\begin{abstract}
The repair of critical-sized defects (CSDs) is a significant challenge in bone tissue engineering. Combining the use of progenitor cells with gene therapy represents a promising approach for bone regeneration. MicroRNAs play important roles in most gene regulatory networks, regulate the endogenous expression of multiple growth factors and simultaneously modulate stem cell differentiation. Our previous study showed that knocking down miR-31 promotes the osteogenesis of bone marrow stromal stem cells (BMSCs). To investigate the therapeutic potential of cells engineered to express anti-miR-31 for CSD repair, lentiviral vectors encoding negative control, miR-31 precursor and anti-sense sequences were constructed and transduced into osteo-inductive BMSCs. The expression of osteogenic-specific genes, alkaline phosphatase activity and Alizarin Red S staining were investigated to evaluate the effects of miR-31 on the cell fate of BMSCs over a 3-week period. In addition, miR-31-modified BMSCs seeded on poly(glycerol sebacate) (PGS) scaffolds were used to repair $8 \mathrm{~mm}$ critical-sized calvarial defects in rats. The results showed that miR-31 suppression significantly increased the expression of osteogenic-specific genes in vitro at the mRNA and protein levels, and that robust new bone formation with high local bone mineral density was observed in the anti-miR groups in vivo. Moreover, the PGS scaffolds carrying anti-miR-31-expressing BMSCs exhibited good biocompatibility and a high regeneration rate $(\sim 60 \%)$ within in vivo bone defects. Our results suggest that miR-31 gene delivery affects the potential of BMSCs for osteogenic differentiation and bone regeneration and that PGS is a potential substrate for genetically modified, tissue-engineered bone in the repair of large bone defects.
\end{abstract}

Keywords: MicroRNA; bone marrow stromal stem cells; critical-sized bone defects; bone regeneration; poly(glycerol sebacate).

* Address for correspondence:

Dr Xianqun Fan

Department of Ophthalmology, Ninth People's Hospital Shanghai Jiao Tong University School of Medicine 639 Zhizaoju Rd, Shanghai, 200011, P. R. China.

Telephone Number: +860212327 1699 ext 5587

FAX Number: +8602163137148

E-mail: fanxq@sh163.net
A critical-sized defect (CSD) is a defect that does not heal spontaneously during the lifetime of the animal (Schmitz and Hollinger, 1986). Strategies to repair bone defects generally focus on preserving equivalent tissue engineering standards to heal CSDs caused by trauma or disease (Al Ruhaimi, 2001; Handa et al., 2012). Osteoconductive and osteo-inductive autografts are the gold standard for the clinical repair of bone defects. However, they have several disadvantages, including infection, pain, loss of function, restricted supply due to the shortage of donors and morbidity (Cui et al., 2007). The use of tissue-engineered bone grafts, which are commonly used for materials and gene therapy, has become a promising therapeutic approach for bone regeneration (Lin et al., 2012; Fu et al., 2013; Liu et al., 2013). Growth factors that stimulate stem cell osteogenesis and angiogenesis play an important role in repairing bone defects with tissueengineered bone. Many factors, such as bone morphogenic proteins (BMPs), vascular endothelial growth factor (VEGF) and hypoxia-inducible factor-1 $\alpha$ (HIF-1 $\alpha$ ), stimulate osteogenesis and angiogenesis in genetically modified, tissue-engineered bone that is placed in bone defects (Zhang et al., 2011; Zou et al., 2012; Ding et al., 2013; Kim et al., 2013; Xiao et al., 2013).

MicroRNAs (miRNAs) are small single-stranded RNA molecules (approximately 22 nucleotides in length) that do not encode protein. Instead, they regulate the expression of proteins by decreasing the level of target messenger RNA (mRNA) or binding to the 3' UTR of target mRNA and inhibiting mRNA translation (Hobert, 2008). Consequently, miRNAs have become important tools in biological and medical research and are increasingly applied to treat and monitor disease. Overexpression or inhibition of miRNAs can simultaneously modulate the endogenous expression of multiple growth factors (Yau et al., 2012). Therefore, delivery of select miRNAs might optimise bone regeneration by coordinating endogenous angiogenesis and osteogenesis (Li et al., 2013). In addition, studies have shown that using miRNA to modify mesenchymal stem cells (MSCs) as seed cells is a promising approach for tissue regeneration (Li et al., 2013; Suh et al., 2013).

Bone mesenchymal stem cells (BMSCs) have the potential to undergo multilineage differentiation into multiple tissue cell types, such as osteoblasts, chondrocytes 
and adipocytes (Pittenger et al., 1999). MicroRNA-31 (miR-31) is involved in regulating tumour cell motility and targets special AT-rich sequence-binding protein 2 (Satb2) in cancer-associated fibroblasts (Aprelikova et al., 2010). Satb2 is a pivotal regulator of multiple osteogenicspecific genes involved in osteoblastic differentiation and bone development (Dobreva et al., 2006). We previously demonstrated that the expression of miR-31 is suppressed in osteo-inductive BMSCs and that knocking down endogenous miR-31 dramatically improves the osteogenic potential of BMSCs (Deng et al., 2013a). In the present study, we explored whether miR-31 regulates Satb2 during the differentiation of BMSCs over a prolonged period. We also investigated whether miR-31-modified BMSCs enhance in vivo bone regeneration in CSD repair.

Polymeric biomaterials play an important role in bone tissue engineering (Rezwan et al., 2006). Ideally, the polymers used in bone tissue engineering should have good biocompatibility, controlled biodegradability, excellent mechanical strength and defined bioactivity (You et al., 2012). Poly(glycerol sebacate) (PGS) is an inexpensive, non-cytotoxic biodegradable polymer (Wang et al., 2002; Chen et al., 2013) that has been investigated for tissue engineering of retinal, neuronal, myocardial and vascular systems (Sundback et al., 2005; Pritchard et al., 2010; Kharaziha et al., 2013; Masoumi et al., 2013). PGS and modified PGS polymers have also been explored for bone tissue engineering. Examples include a PGS-bioglass composite for the repair of injured bone (Chen et al., 2010) and a PGS/hydroxyapatite composite for bone regeneration (Bodakhe et al., 2013).

In our recently published data (Zaky et al., 2014), a critical size defect in ulna of rabbit was healed by employing the elastomeric polymer, the results show that PGS elastomer is an auspicious osteoconductive material for the regeneration of bony defects. Also, our studies (Wu et al., 2011; Lee et al., 2013) showed that PGS induces angiogenic differentiation of bone marrow mononuclear cells and performed well in vascular tissue engineering. Furthermore, the process of angiogenesis usually coupled with osteogenesis in tissue engineering strategies (Kanczler and Oreffo, 2008; Nguyen et al., 2012). Compared to a ceramic material such as $\beta$-tricalcium phosphate ( $\beta$-TCP) with good osteo-inductive capacity (Yuan et al., 2007), PGS promotes bone regeneration coupling with angiogenesis. As stated above, PGS scaffold is a hopeful candidate for tissue engineering of bone. In the present study, we used PGS as a scaffold to provide the ingrowth space and microenvironment for transplanted cells.

We combined porous PGS scaffolds and BMSCs that were modified by miR-31 or by anti-sense treatment to repair large bone defects. Here, we describe how BMSCs modified by miR-31 gene therapy and grown on a PGS scaffold can be used to promote the repair of large CSDs in a rat skull model.

\section{Materials and Methods}

\section{Cell culture}

Bone marrow was harvested from the femora and tibiae of 4-week-old male Fischer 344 rats according to a reported protocol (Soleimani and Nadri, 2009). The isolated BMSCs were cultured in Dulbecco's modified Eagle's medium (DMEM) (Gibco, Grand Island, NY, USA) containing $10 \%$ foetal bovine serum (FBS) (Gibco) and 100 units $/ \mathrm{mL}$ penicillin at $37{ }^{\circ} \mathrm{C}$ in an atmosphere of $5 \% \mathrm{CO}_{2}$. BMSCs were subcultured using $0.25 \%$ trypsin containing $0.02 \%$ EDTA. For osteo-inductive differentiation, the culture medium was supplemented with $10^{-8} \mathrm{M}$ dexamethasone, $10 \mathrm{mM} \beta$-glycerol phosphate and $50 \mathrm{mg} / \mathrm{mL}$ of L-ascorbic acid (Sigma, St. Louis, MO, USA). Flow cytometry was used to characterise the BMSCs according to their CD31, CD34, CD90 and CD105 staining (BD Biosciences) as previously described (Zou et al., 2011a).

\section{Lentiviral vector construction and gene transduction}

For miR-31 overexpression, the precursor sequence for miR-31 was amplified from the genomic Rattus DNA by polymerase chain reaction (PCR) including overhang sequences from a 5' BamH1 and a 3' EcoR1-restriction site and cloned into hU6-MCS-PGK-EGFP lentiviral vectors (Hanbio, Shanghai, China). For miR-31 inhibition, self-complementary DNA oligonucleotides (anti-miR) encompassing the sequence Rattus miR-31 and irrelevant sequence (negative control, miR-Neg) were chemically synthesised including the same restriction sites as miR-31 precursor. The sense and anti-sense oligomers were annealed then inserted into hU6-MCS-PGK-EGFP lentiviral vectors as well. Both of the recombinant lentiviruses were produced by co-transfection of 293 T cells with plasmids PSPAX2 and PMD2G using Lipofectamine 2000 (Invitrogen, Carlsbad, CA, USA). Lentivirus-containing supernatants were harvested $48 \mathrm{~h}$ after transfection and filtered through $0.22 \mu \mathrm{m}$ cellulose acetate filters (Millipore, Billerica, MA, USA). Recombinant lentiviruses were concentrated by ultracentrifugation ( $2 \mathrm{~h}$ at 50,000 g). For transduction, lentiviral vectors encoding miR-31, anti-miR and miR-Neg were added to reach an MOI of 50, BMSCs were incubated with the lentiviruses and $8 \mu \mathrm{g} / \mathrm{mL}$ polybrene for $24 \mathrm{~h}$. The transduction efficiency of the lentiviruses was calculated from the proportion of GFP-positive BMSCs determined using flow cytometry. The miR-31 expression levels in the gene-modified cells at various time points were determined using qPCR analysis.

\section{Quantitative real-time RT-PCR analysis (qPCR)}

The total RNA was extracted from the transfected BMSCs using TRIzol reagent (Invitrogen), and cDNA was synthesised using the PrimeScript RT reagent kit (TaKaRa, Dalian, China). The qPCR was performed using Power SYBR Green PCR Master Mix (Applied Biosystems, Foster City, CA, USA) and a 7500 Real-Time PCR Detection System. The sequences of the primers for the osteogenic marker genes, including runt-related transcription factor 2 (Runx2), special AT-rich sequence binding protein 2 (Satb2), osteopontin (Opn) and osteocalcin (Ocn), as well 
as GAPDH, were previously reported (Deng et al., 2013a). The expression levels of mature miR-31 were determined using a miRcute miRNA qPCR detection kit (Tiangen Biotech, Beijing, China). The relative mRNA and miRNA levels were normalised to the expression of GAPDH and U6, respectively, and then presented as the fold change relative to expression in miR-Neg-transduced cells.

\section{Western blot analyses}

One day after transduction by lentiviruses, the BMSCs were seeded into 6-well plates and cultured in osteoinductive medium. The cultured cells were harvested and lysed using radioimmunoprecipitation assay lysis buffer (Thermo Fisher Scientific, Waltham, MA, USA) at various time points after gene transduction. The total protein concentrations were determined using a BCA protein assay (Thermo). Equal amounts of cell lysates were separated on a $9 \%$ SDS-PAGE gel and transferred to $0.22 \mu \mathrm{m}$ polyvinylidene fluoride membranes (Millipore). After blocking with $5 \%$ non-fat milk, the membranes were probed with primary antibodies directed against Runx2, Satb2, Opn, Ocn and $\beta$-actin (Abcam, Cambridge, MA, USA) overnight at $4{ }^{\circ} \mathrm{C}$. The membranes were then incubated with horseradish peroxidase (HRP)-conjugated secondary antibodies (Sigma). The immunoblots were visualised using an Odyssey V3.0 image scanner (LI-COR, Lincoln, NE, USA). The densitometric intensities of the individual immuno-labelled bands were quantified using Image J software, and the values were normalised relative to $\beta$-actin. The results are reported as the mean values \pm SD.

\section{Alkaline phosphatase activity and Alizarin Red S staining}

After BMSCs were transduced, they were seeded into 12well plates at a density of $1.0 \times 10^{5}$ cells/well and cultured in osteo-inductive medium. Alkaline phosphatase (ALP) staining was performed according to the manufacturer's instructions (Rainbow, Shanghai, China) at day 7 (Xia et al., 2011). Semiquantitative analysis of ALP activity was performed as previously reported (Su et al., 2012). Briefly, after the cells were lysed, the total protein content of the samples was determined using a BCA protein assay kit. ALP activity was detected from the absorbance at $405 \mathrm{~nm}$ using p-nitrophenyl phosphate (p-NPP) (Sigma) as the substrate. After fixation in $95 \%$ ethanol, the cells were incubated with $40 \mathrm{mM}$ Alizarin Red S (ARS) staining solution (Sigma) for $20 \mathrm{~min}$ at room temperature on day 14 For ARS measurement, the stain was desorbed using $10 \%$ cetylpyridinium chloride (Sigma) for $1 \mathrm{~h}$. The solution was collected and distributed at $100 \mu \mathrm{L} /$ well in a 96-well plate. Absorbance readings at $590 \mathrm{~nm}$ were obtained using a spectrophotometer (Thermo). Finally, the ALP and ARS levels were normalised to the total protein content.

\section{Fabrication of PGS scaffolds}

PGS synthesis was an improvement of an existing procedure (Wang et al., 2002). Porous PGS scaffolds were prepared using a modified salt fusion method (Gao et al., 2006). Briefly, ground salt particles of 300-500 $\mu \mathrm{m}$ (300$355 \mu \mathrm{m} / 355-500 \mu \mathrm{m}$ at $1 / 1 \mathrm{w} / \mathrm{w}$, salt $\%=95 \mathrm{wt} \%$ ) were used as the porogens for the salt fusion. The thickness of the salt layer, which determined the thickness of the final scaffold, was easily adjusted by inserting a combination of shims of different thicknesses. The physical properties of PGS scaffolds, such as their mechanical properties and the porosity, have been systematically investigated before (Gao et al., 2006; Crapo et al., 2008; Wu et al., 2011). Finally, the disc-shaped ( $\Phi 8 \mathrm{~mm} \times 2 \mathrm{~mm}^{3}$ ) porous PGS scaffolds were used for cell seeding. Twenty-four hours after a total of $2 \times 10^{6}$ freshly trypsinised BMSCs were seeded on each PGS scaffold as previous described (Gao et al., 2007), the cell-seeded scaffolds were subjected to scanning electron microscopy (SEM) (Philips, Amsterdam, Netherlands) (Crapo et al., 2008).

\section{Animal experiments}

All of the procedures were approved by the Animal Research Committee of the Ninth People's Hospital of the Shanghai Jiao Tong University School of Medicine. After general anaesthesia, the head of each 12-week-old male Fischer 344 rat was shaved and sterilised with $70 \%$ ethanol. The cranium was exposed by a medial incision through the scalp and periosteum and blunt dissection to reach the calvarium. A critical-sized round bony defect was created in each rat using a dental trephine $(8 \mathrm{~mm}$ external diameter) (Nouvag AG, Goldach, Switzerland). PGS scaffolds seeded with syngenic cells transduced with miR-Neg, miR-31 or anti-miR genes were implanted into the defects after $24 \mathrm{~h}$ of in vitro culture. Finally, the wound was irrigated, the fascia was sutured, and the skin was closed. Twenty-four rats were randomly assigned to one of the following four different experimental groups: (1) PGS $(n=6),(2)$ PGS with BMSCs/miR-Neg $(n=6)$, (3) PGS with BMSCs/miR-31 $(n=6)$, and (4) PGS with BMSCs/anti-miR $(n=6)$.

\section{Micro-computed tomography analysis (micro-CT)}

The animals were euthanised under general anaesthesia eight weeks after surgery, and the skulls were explanted and fixed in $4 \%$ paraformaldehyde. The morphology of the reconstructed skulls was determined using micro-CT ( $\mu$ CT-80, Scanco Medical, Bassersdorf, Switzerland) with some of the same parameters described previously (Zou et al., 2011a), including X-ray tube potential of $80 \mathrm{kV}$, tube current of $0.45 \mathrm{~mA}$ and $15 \mathrm{~mm}$ voxel resolution. A cylindrical region of interest (ROI), with a diameter of $8 \mathrm{~mm}$ and a height that covered the entire thickness of the calvarial bone in defects, was selected for analysis. After micro-CT scanning, the skulls were visualised using software (MicroView, GE Healthcare, Waukesha, WI, USA) that performed three-dimensional isosurface rendering. Micro-CT measurements included the ratio of new bone volume relative to the tissue volume (BV/TV) and bone mineral densities (BMDs) of the bone defect.

\section{Histological and histomorphometric observation}

The skulls were harvested and fixed in a $5 \%$ neutral buffered formalin solution. After dehydration in increasing concentrations of alcohol ( $75 \%$ to $100 \%)$, the undecalcified specimens were embedded in polymethylmethacrylate. Three $150 \mu \mathrm{m}$ sagittal sections of the central segment were cut using a microtome (Leica, Hamburg, Germany) 

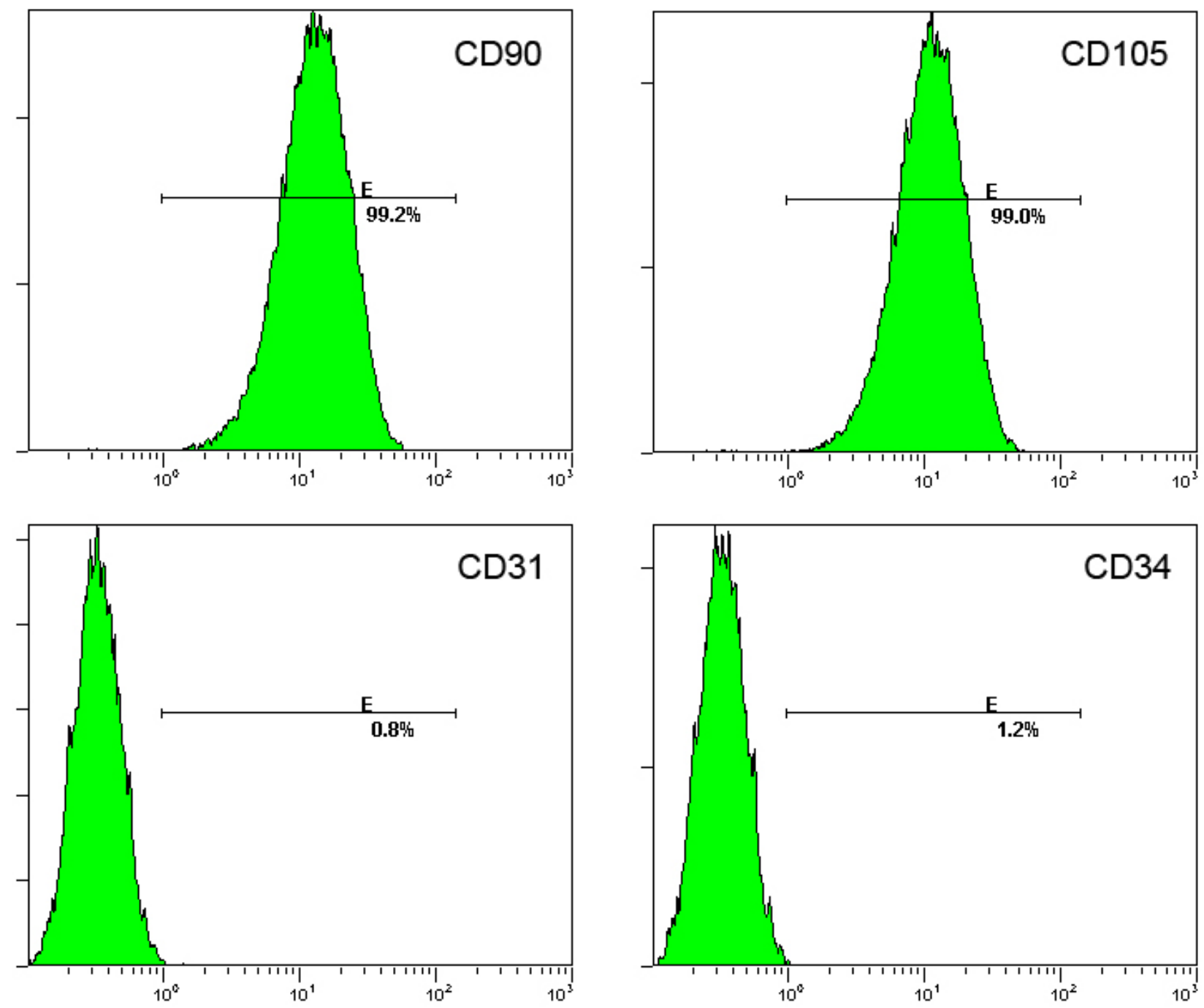

Fig. 1. Identification of BMSCs. Flow cytometry shows that the BMSCs expressed CD90 (99.21 $\pm 2.31 \%)$ and CD105 (99.06 $\pm 1.72 \%)$ at high levels. In contrast, a low expression of the haematopoietic lineage markers CD31 $(0.8 \pm 0.45 \%)$ and CD34 (1.2 $\pm 0.31 \%)$ was observed.

and hand-ground and polished to a final thickness of approximately $40 \mu \mathrm{m}$. The sections were then stained with van Gieson's picrofuchsin to detect new bone formation. Red staining indicated new bone formation, whereas PGS appeared yellow. The surface area of the newly formed bone and PGS residue in the raised area eight weeks after the operation were calculated based on the entire area of the bone defect using the image analysis system Image-Pro Plus $^{\mathrm{TM}}$ (Media Cybernetics, Silver Springs, MD, USA).

\section{Statistical analysis}

All of the in vitro studies were performed in triplicate unless otherwise specified. The data are expressed as the mean values $\pm \mathrm{SD}$. Statistical analysis was performed by ANOVA and SNK post hoc or Kruskal-Wallis nonparametric procedure followed by Mann-Whitney $\mathrm{U}$ test for multiple comparisons based on the normal distribution and equal variance assumption test, using SPSS v 17.0 statistical software package. The difference was considered statistically significant when $p$ value is less than 0.05. The miR-Neg group was compared with the
miR-31 group (designated as $* p<0.05$ and $* * p<0.01$ ), and the anti-miR group was compared with the miR-Neg group (designated as $\# p<0.05$ and $\# \# p<0.01$ ).

\section{Results}

Characterisation and gene transduction of BMSCs Flow cytometry of isolated BMSCs showed high expression levels of the MSC markers CD90 and CD105, whereas the myeloid endothelial cell marker CD31 and haematopoietic lineage marker CD34 were rarely detected (Fig. 1). Four days after the BMSCs were transduced by lentiviruses encoding miR-Neg, miR-31 or anti-miR genes, emission of green fluorescence was observed by fluorescence microscopy (Fig. 2a). The efficiency of lentiviral transduction, which was calculated from the proportion of GFP-positive BMSCs detected by flow cytometry, was $88.32 \pm 4.09 \%$ (Fig. 2b). The qPCR results showed that from day 4 to 21 , miR-31 was significantly overexpressed in the miR-31 group and repressed in 

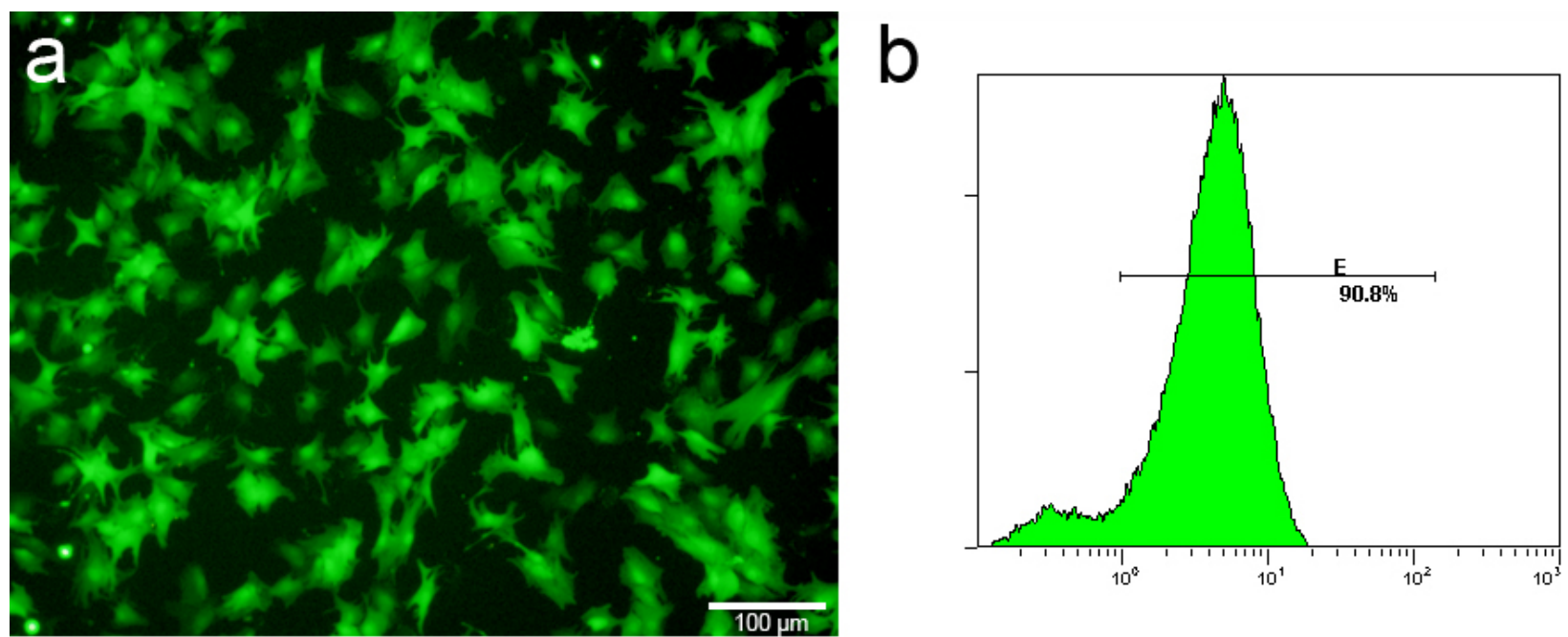

C

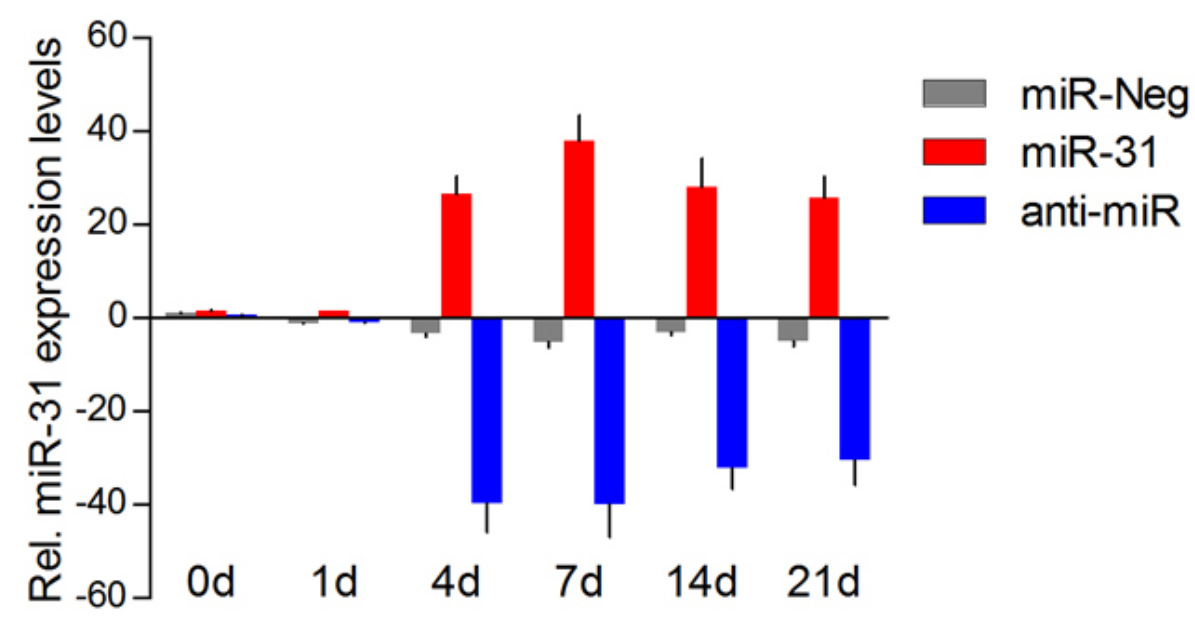

Fig. 2. Characterisation of gene-transduced BMSCs. (a) Fluorescence microscopy shows GFP-positive BMSCs after transfected with lentiviral vectors. The scale bar represents $100 \mu \mathrm{m}$. (b) The transduction efficiency of lentiviruses was determined by the GFP-positive ratio of the BMSCs $(90.8 \pm 3.03 \%)$ using flow cytometry. (c) miR-31 was overexpressed in the miR-31 group and repressed in the anti-miR group when compared with the miR-Neg group from days 4 to $21(p<0.05)$.

a

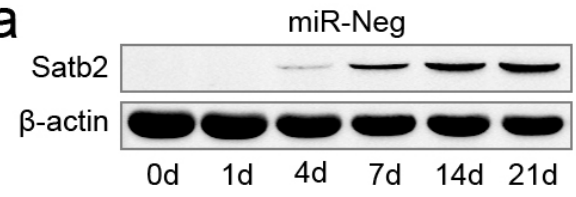

miR-31

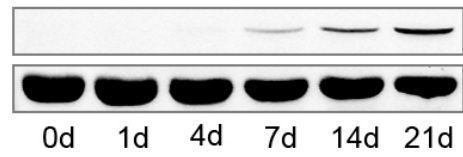

anti-miR

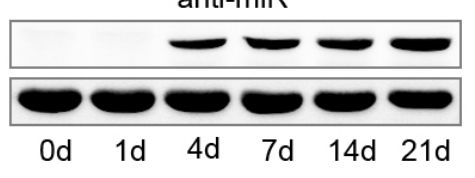

b
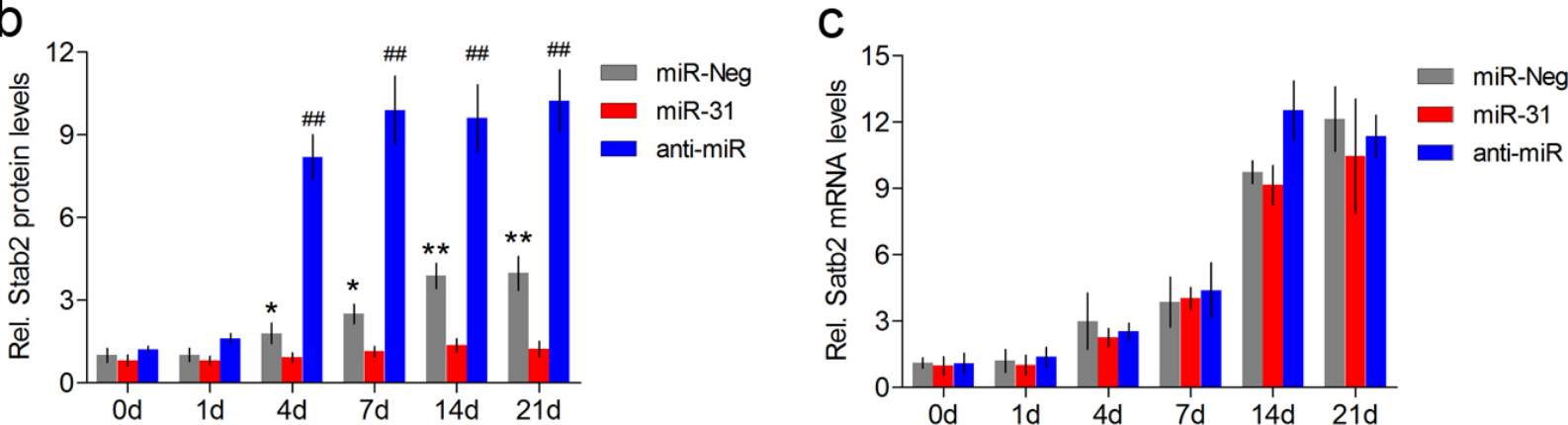

Fig. 3. Effect of miR-31 modification on Satb2 expression. (a) The increasing trend of Satb2 protein levels was counteracted by miR-31 overexpression or accelerated by knockdown of miR-31 during osteo-induction. (b) The semiquantitative analysis of the Satb2 protein levels (the miR-Neg group was compared with the miR-31 group, ${ }^{*} p<0.05$ and ${ }^{* *} p<0.01$; the anti-miR group were compared with the miR-Neg group, $\# p<0.05$ and \#\# $p<0.01$ ). (c) The mRNA levels of Satb2 were not altered by miR-31 modification. 

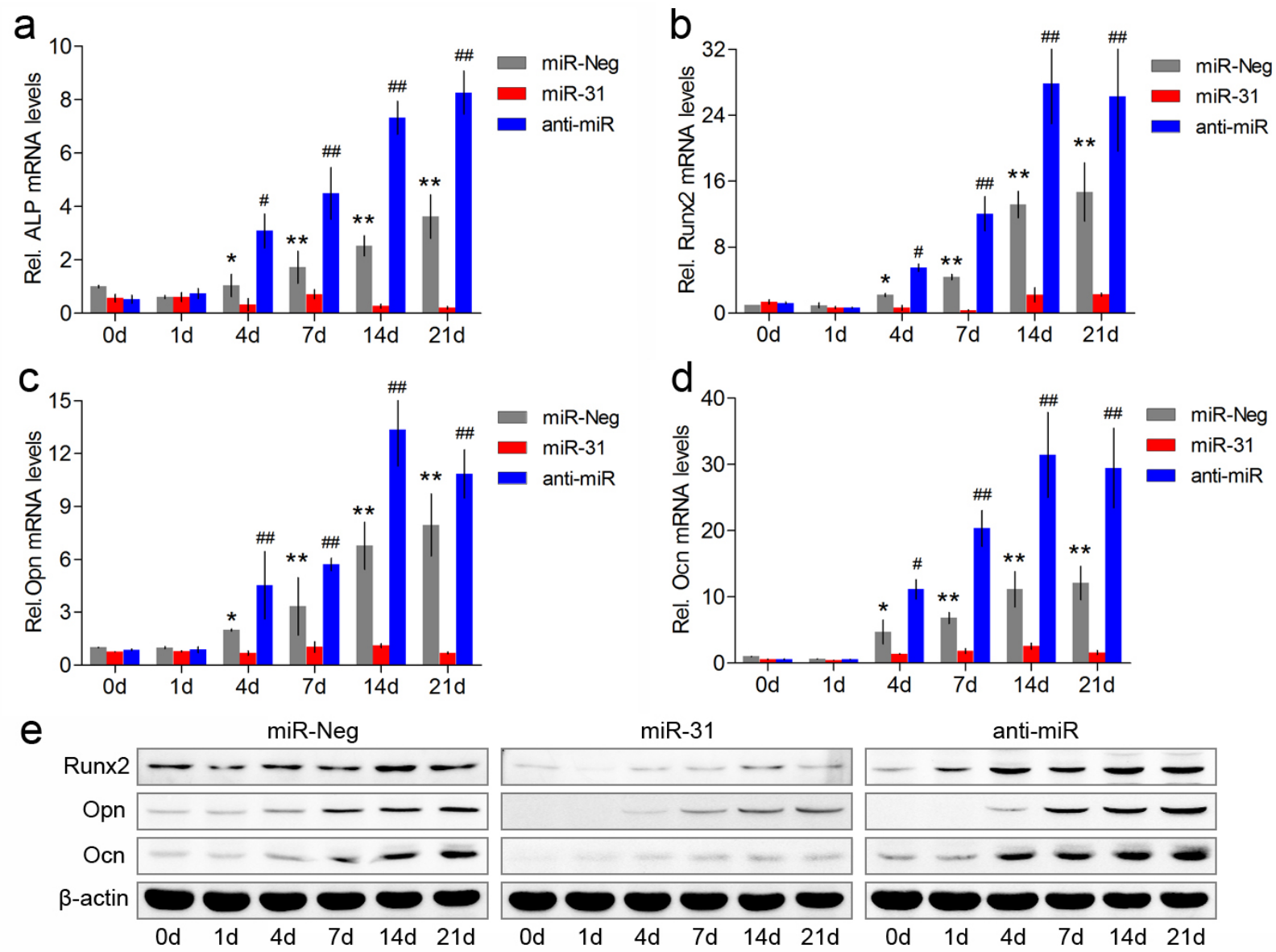

Fig. 4. Expression of osteogenic-specific markers in gene-transduced BMSCs. (a-d) The mRNA levels of key osteogenic-specific markers ALP, Runx2, Opn and Ocn in the miR-Neg group, miR-31 group and anti-miR group within 3 weeks. (e) The protein levels of Runx2, Opn and Ocn show the same pattern with qPCR findings (the miRNeg group was compared with the miR-31 group, ${ }^{*} p<0.05$ and ${ }^{* *} p<0.01$; the anti-miR group were compared with the miR-Neg group, $\# p<0.05$ and $\# \# p<0.01)$.

the anti-miR group compared with the miR-Neg group $(p<0.05)$ (Fig. 2c).

\section{Regulation of Satb2 expression by miR-31}

We next evaluated whether miR-31 regulates Satb2 expression during osteogenic differentiation of BMSCs. BMSCs transduced by lentiviruses encoding miR-Neg, miR-31 or anti-miR were subjected to qPCR and western blotting $0,1,4,7,14$ and $21 \mathrm{~d}$ after being transferred to osteo-inductive medium. Western blot analysis revealed that Satb2 protein expression increased gradually from day 4 to 21 of osteogenic induction. However, this trend was significantly counteracted by the overexpression of miR-31. In contrast, increased Satb2 expression was dramatically accelerated by knocking down miR-31 expression (Fig. 3a). Semiquantitative analysis showed that from day 4 to 21, Satb2 protein levels were depressed and elevated approximately 2.5 -fold in cells modified by $\mathrm{miR}-31$ and anti-miR, respectively, relative to miRNeg-modified cells $(p<0.05)$ (Fig. 3b). This suggests that miR-31 is an important negative regulator of Satb2 expression. However, the qPCR results indicated that the levels of Satb2 mRNA in the miR-31-modified BMSCs were not significantly altered by miR-31 overexpression or suppression during osteogenic induction $(p>0.05)$ (Fig. $3 c)$. It follows that miR-31 negatively modulates Satb2 expression by targeting translational but not transcriptional control.

\section{Osteogenic differentiation of miR-31-modified BMSCs}

To further assess how miR-31 mediates Satb2 protein expression during osteogenic differentiation of BMSCs transduced with miR-Neg, miR-31 or anti-miR constructs and cultured in osteo-inductive medium, a series of analyses, including qPCR, western blotting and ALP or ARS staining were performed at various time points. The mRNA levels of the osteogenic-specific markers ALP, Runx2, Opn and Ocn gradually increased in the miR-Neg group from day 4 to 21 (Fig. 4a-d). Notably, the mRNA expression of these markers in the anti-miR group was initially higher than that of the miR-Neg group on day $4(p<0.05)$ and dramatically increased from day 7 to $21(p<0.01)$. Interestingly, the miR-31 overexpression group showed no significant difference in the mRNA levels of osteogenic factors between the various time points $(p>0.05)$. The results of osteogenic protein analysis were in accordance with the corresponding qPCR findings (Fig. 
a

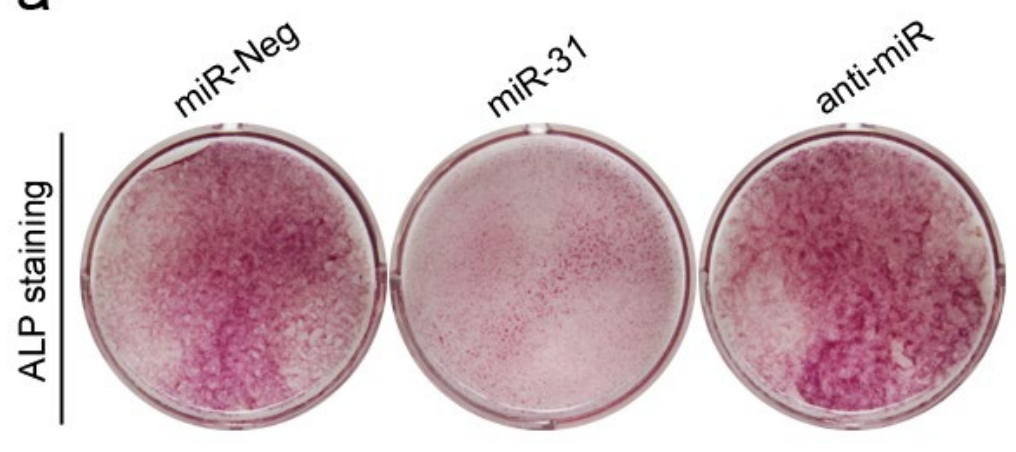

C

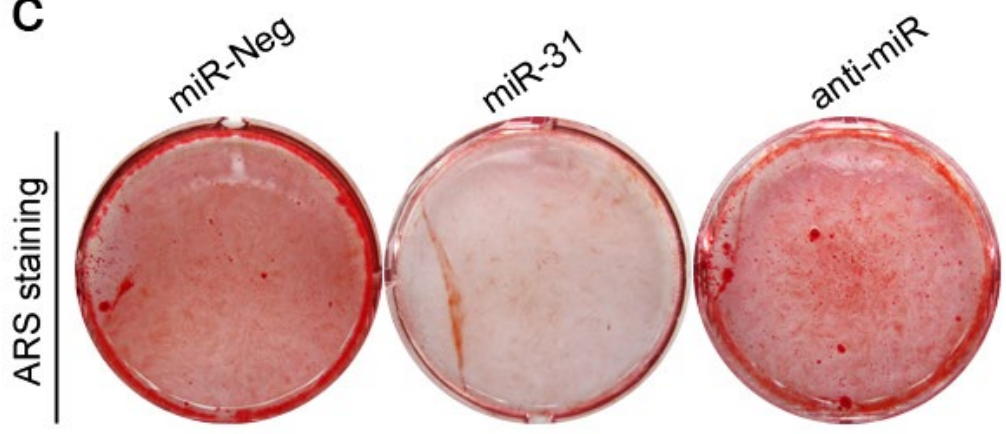

b

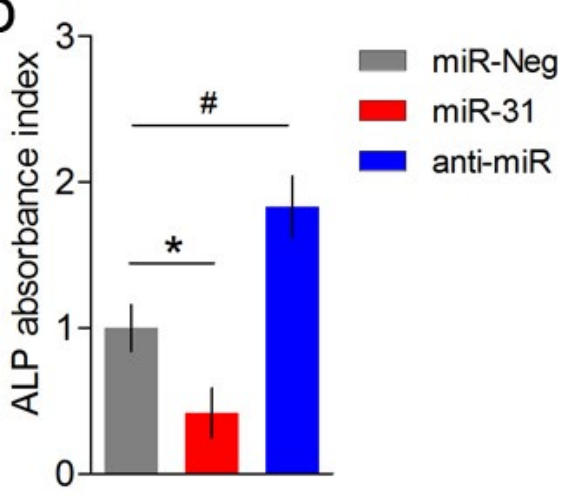

d

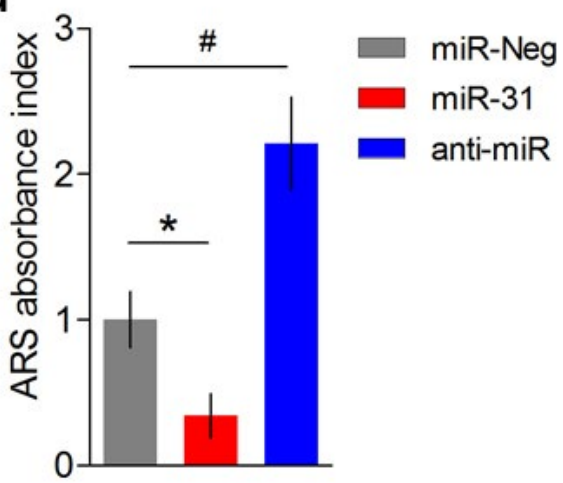

Fig. 5. Results of ALP and ARS staining. (a, c) ALP expression on day 7, and ARS staining on day 14. (b, d) Semiquantitative analysis of ALP and ARS staining $(* p<0.05 ; \# p<0.05)$.
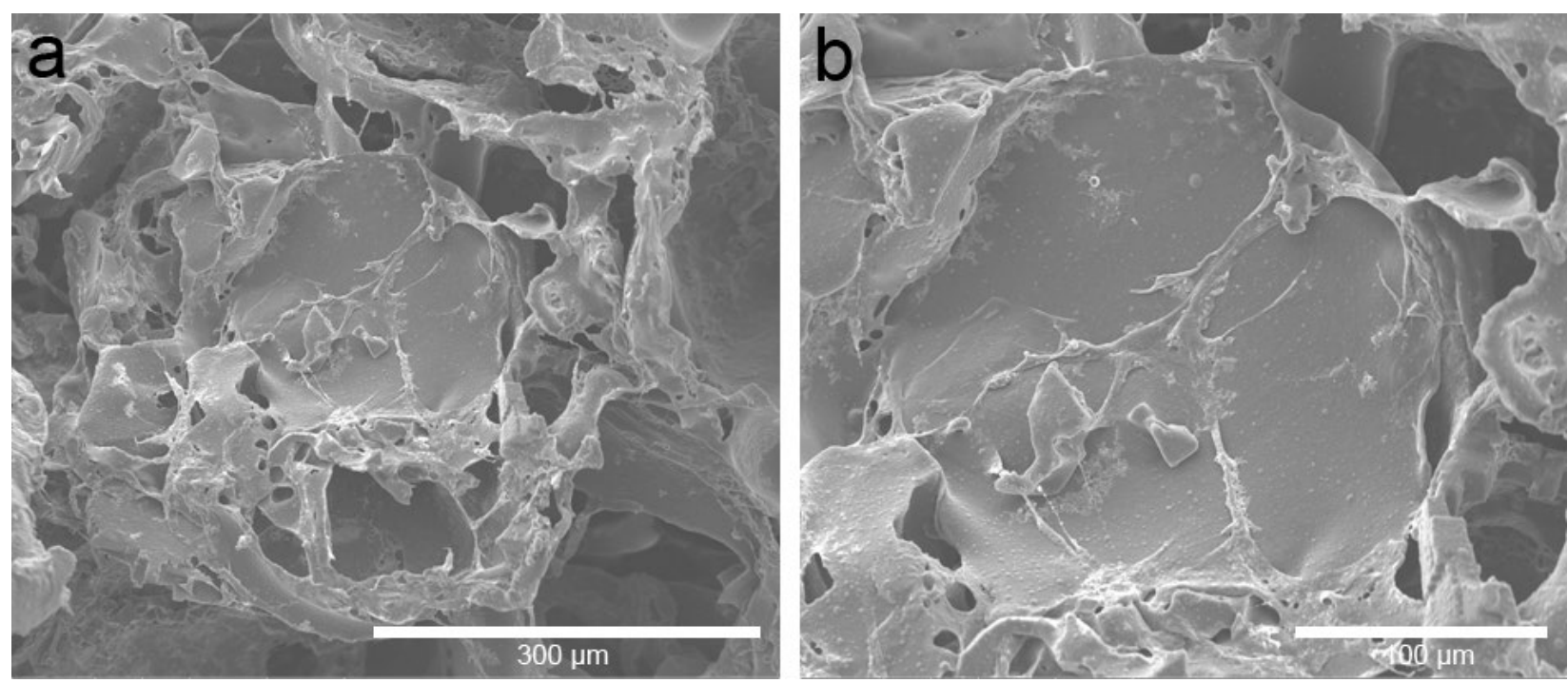

Fig. 6. The composites were submitted to SEM imaging and cells were attached to the surface of the scaffold. The scale bars represent $300 \mu \mathrm{m}$ in a and $100 \mu \mathrm{m}$ in $\mathbf{b}$.

4e). Furthermore, semiquantitative analysis of the western blot results showed that the expression of Runx2, Opn and Ocn decreased and increased nearly 3-fold from day 4 to 21 in the miR-31 and anti-miR groups, respectively, relative to the miR-Neg group.

Seven days after transduction, ALP staining was attenuated in the miR-31 group and enhanced in the antimiR group (Fig. 5a). Furthermore, ARS staining on day 14 revealed a dramatic impairment in calcium deposition in the miR-31 group but a significant enhancement in the anti-miR group (Fig. 5c). Semiquantitative analysis showed that on day 7, ALP activity in the miR-31 and anti-miR-31 groups was nearly 2-fold lower and higher, respectively, than in the miR-Neg group (Fig. 5b) (p < 0.05). Additionally, semiquantitative analysis of ARS staining showed the same pattern as ALP activity (Fig. $5 d)(p<0.05)$. Altogether, these data suggest that miR31 plays a pivotal role in regulating the osteo-inductive differentiation of BMSCs. 
a
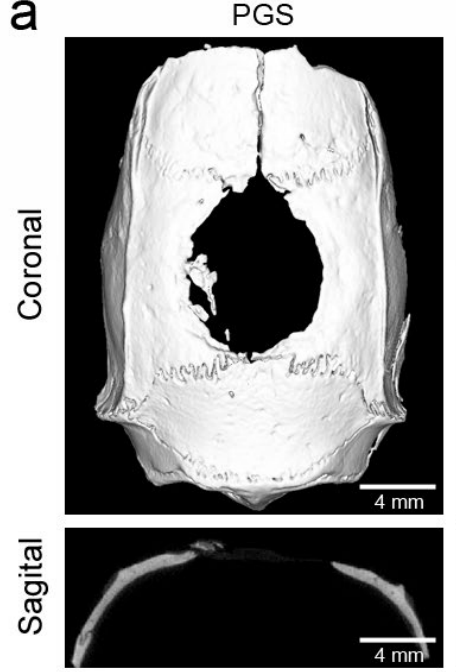

b

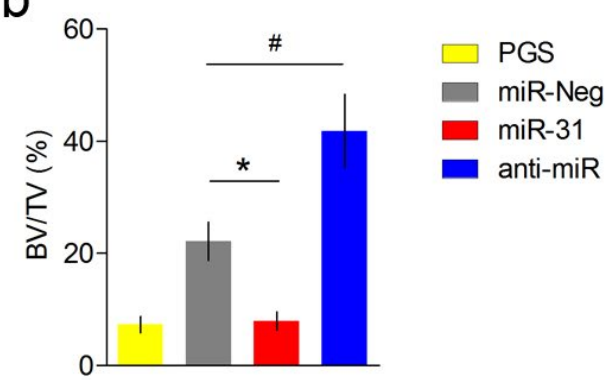

miR-Neg
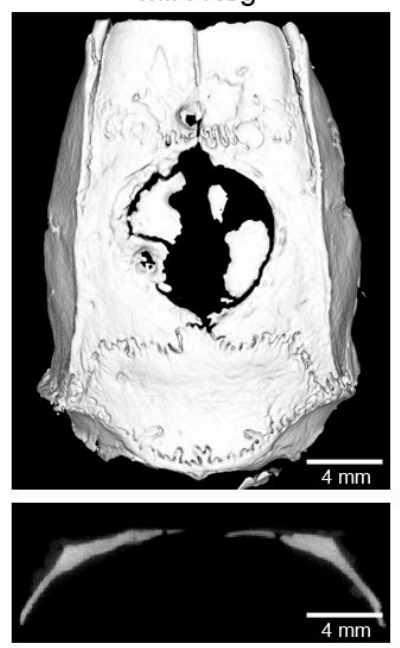

\section{C}

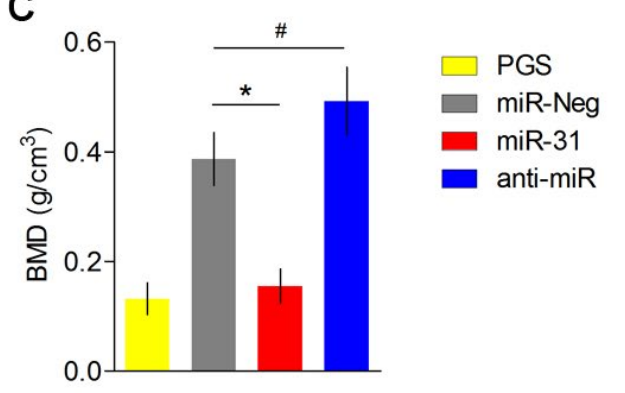

Fig. 7. Analysis of micro-CT imaging. (a) Coronal and sagittal views of the harvested skulls at 8 weeks postimplantation (from left to right: PGS, miR-Neg/BMSCs/PGS, miR-31/BMSCs/PGS, anti-miR/BMSCs/PGS). The scale bars represent $4 \mathrm{~mm}$. (b, c) Bone mineral density (BMD) and bone volume/total volume (BV/TV) show differences between various groups $(* p<0.05 ; \# p<0.05)$.

\section{Effect of miR-31 expression on in vivo bone regeneration}

Twenty-four hours after the BMSCs were seeded onto PGS scaffolds, the composites were imaged using SEM. SEM showed that the cells were attached to the surfaces of the scaffolds (Fig. 6). We next explored whether miR-31based modulation of osteogenic differentiation affects bone regeneration in vivo. Twenty-four hours after the scaffolds were seeded with BMSCs, four groups of composites (PGS, PGS with BMSCs/miR-Neg, PGS with BMSCs/miR-31, and PGS with BMSCs/anti-miR) were transplanted into the $8 \mathrm{~mm}$ CSDs in the rat calvarial model.

To observe new bone formation within the bone defects, the morphology of the newly formed bone was determined by micro-CT eight weeks postoperatively. In coronal and sagittal micro-CT images, the extent of new bone formation varied significantly between the four groups (Fig. 7a). In particular, new bone formation in the anti-miR group was greater than that in the PGS, miR-31 and miR-Neg groups. The quantity of newly formed bone within the defects was calculated using morphometric analysis. The BV/TV ratio in the miR-Neg group (22.18 $\pm 3.39 \%$ ) was markedly higher than that in the miR-31 group $(7.93 \pm 1.62 \%)(p<0.05)$ but significantly lower than that in the anti-miR group (41.82 $\pm 6.54 \%$ ) (Fig. $7 b)$ $(p<0.05)$. Additionally, the BMDs in the four groups $\left(0.132 \pm 0.029 \mathrm{~g} / \mathrm{cm}^{3}\right.$ in the PGS group, $0.387 \pm 0.048 \mathrm{~g} /$ $\mathrm{cm}^{3}$ in the miR-Neg group, $0.155 \pm 0.031 \mathrm{~g} / \mathrm{cm}^{3}$ in the miR31 group and $0.492 \pm 0.062 \mathrm{~g} / \mathrm{cm}^{3}$ in the anti-miR group) exhibited the same pattern as the BV/TV ratios (Fig. 7c). These findings suggest that miR-31 impairs bone repair and that anti-miR-31 greatly increases the bone regeneration potential of BMSCs.

\section{Histological analysis of bone regeneration}

The histological results obtained from van Gieson staining of non-decalcified specimens supported the micro-CT findings (Fig. 8a). Light microscopy revealed that the percentage of new bone area after eight weeks was 15.72 $\pm 2.55 \%$ in the PGS group, $35.34 \pm 4.42 \%$ in the miRNeg group, $13.82 \pm 3.42 \%$ in the miR-31 group and 60.92 $\pm 7.34 \%$ in the anti-miR group (Fig. 8b). The percentage of the residual PGS scaffold area was $46.32 \pm 6.85 \%$ in the PGS group, $23.34 \pm 4.67 \%$ in the miR-Neg group, 47.93 $\pm 7.58 \%$ in the miR-31 group and $12.82 \pm 2.54 \%$ in the anti-miR group (Fig. 8c). Altogether, these data indicate that miR-31 attenuates ossification by BMSCs and that knocking down miR-31 promotes new bone formation. 

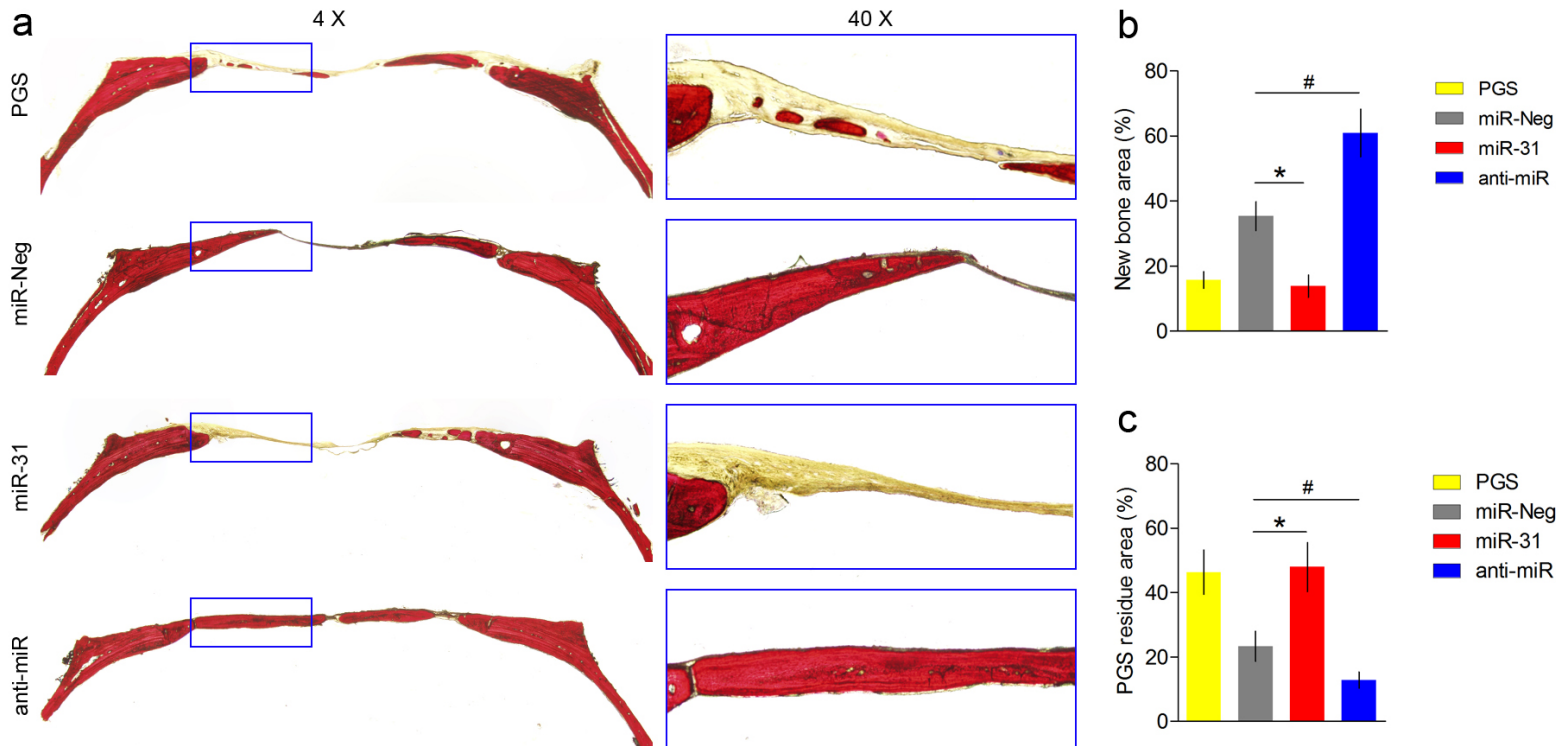

Fig. 8. Histological analysis of new bone formation and PGS residue using van Gieson's picrofuchsin staining. (a) From top to bottom: PGS, miR-Neg/BMSCs/PGS, miR-31/BMSCs/PGS, anti-miR/BMSCs/PGS. New bone appears red, and PGS appears yellow. $(\mathbf{b}, \mathbf{c})$ The percentages of the new bone area and PGS residue area show differences between the various groups $\left({ }^{*} p<0.05 ; \# p<0.05\right)$.

\section{Discussion}

Tissue engineering of bone is a new therapeutic strategy for repairing bone tissue defects. Genetic therapy to enhance bone regeneration has become one of the most active areas in bone tissue engineering (Ye et al., 2011; Zou et al., 2011a). In this study, we developed functional tissue-engineered bone by incorporating miR-31-modified BMSCs into PGS scaffolds. Anti-miR modification significantly improved the expression of osteogenicspecific marker genes and enhanced the osteogenesis of BMSCs as confirmed by qPCR, western blotting and ALP and ARS staining. The repair of $8 \mathrm{~mm}$ full-thickness cranial bone defects in vivo further demonstrated that anti-miR is superior to miR-Neg for bone regeneration mediated by gene delivery, likely due to the role of anti-miR in facilitating the osteogenic differentiation of exogenous BMSCs.

Luciferase reporter assays have shown that direct targeting of Satb2 mRNA by miR-31 is involved in regulating tumour cell motility (Aprelikova et al., 2010). Our results showed that during three weeks of osteogenic induction, increased Satb2 protein expression was significantly counteracted by miR-31 overexpression and accelerated by miR-31 suppression relative to miR-Negtransduced BMSCs. However, the levels of Satb2 mRNA were not significantly altered by miR-31 expression. These data confirmed that miR-31 regulates Satb2 expression at the translational but not transcriptional level and that this mechanism is in effect during cell differentiation and cancer metastasis. Additionally, our data showed that the expression of Runx2, Opn and Ocn followed the same pattern as Satb2 protein expression, which is consistent with previous studies that have demonstrated that Satb2 gene delivery accelerates the expression of osteogenic specific genes (Runx2, Opn and Ocn) and promotes bone regeneration (Yan et al., 2011; Ye et al., 2011). Moreover, micro-CT showed that anti-miR-31 treatment significantly improved ossification in the calvarial model. In contrast, only rare new bone formation was observed in the PGS and miR-31 groups. Quantitative analysis revealed that the $\mathrm{BV} / \mathrm{TV}$ ratio and the BMD of the anti-miR group were significantly higher than those of the PGS, miR-31 and miR-Neg groups. Overall, the results of our investigation of differentiated osteogenic BMSCs suggested that miR-31 plays a pivotal role in bone regeneration.

Our previous study showed that porous $\beta$-tricalcium phosphate $(\beta$-TCP) seeded with adipose-derived stem cells (ASCs) expressing miR-31 anti-sense for the repair of rat calvarial CSDs (5 mm diameter) achieved an approximately $40 \%$ osteo-regeneration rate (Deng et al., $2013 \mathrm{~b}$ ). In the present study, the rate of bone regeneration in an $8 \mathrm{~mm}$ rat calvarial CSD was approximately $60 \%$ in the anti-miR group. Why does a higher regeneration rate occur in relatively larger bone defects? This may be due to the properties of the seeded cells and the scaffold material. A series of assays have shown that the osteogenic potential of BMSCs is greater than that of ASCs both in vitro and in vivo (Mizrahi et al., 2013). Furthermore, our previous studies show that PGS could induce differentiation of bone marrow mononuclear cells to vascular cells and promote vascular tissue formation by adsorbing plasma proteins and platelets (Wu et al., 2011; Lee et al., 2013). Additionally, the process of angiogenesis is coupled with osteogenesis in bone tissue regeneration (Kanczler and Oreffo, 2008; Nguyen et al., 2012). Therefore, the features of angiogenic 
induction of PGS unlike with $\beta$-TCP may interpret the aforementioned phenomenon too. PGS scaffold may be a better candidate than $\beta$-TCP for tissue engineering bone.

PGS is degraded by surface erosion, with simultaneous loss of linear mass and strength occurring during the resorption period. These properties are excellent for biomaterials used in bone tissue engineering. In our previous study, when implanted subcutaneously, the degradation half-life of PGS was $21 \mathrm{~d}$, and complete resorption was observed by day 60 (Wang et al., 2003). Although PGS was not completely absorbed after eight weeks in the experimental groups of the present study, the highest PGS biodegradation rate, which occurred in the anti-miR group, was associated with the best bone regeneration rate. As tissue ingrowth gradually proceeds, more giant cells participate in silk gel degradation, resulting in more space for tissue ingrowth (Zhang et al., 2011). These results are consistent with those of another study showing that the microenvironment of bone formation and the extracellular matrix (ECM) facilitate osteoclast adhesion, mineral resorption and scaffold degradation (Mastrogiacomo et al., 2007). Although PGS appears to be a good candidate material for tissue-engineered bone, its potential in bone repair must be assessed using a broad array of in vitro and in vivo biocompatibility assays.

BMSCs are multipotent stem cells that can differentiate into osteoblasts, chondrocytes and adipocytes (Pittenger et al., 1999). In this study, we systematically explored the potential of miR-31-modified BMSCs grown on a PGS scaffold to repair large bone defects. Although knocking down miR-31 expression significantly enhanced the osteogenic differentiation and bone regeneration of BMSCs, the biological role of miR-31 in modulating multipotent differentiation of BMSCs requires further clarification. Moreover, the effects of PGS on ossification in tissue engineered bone must be further evaluated.

\section{Conclusions}

In this study, we showed that miR-31 negatively regulates the osteogenic differentiation of BMSCs by targeting the pivotal transcription factor Satb2. Anti-miR-31 significantly increased the osteogenic potential of BMSCs that are dependent on the prolonged overexpression of Satb2 protein. PGS is a potential candidate scaffold for bone tissue engineering. Modification of BMSCs on a PGS scaffold with anti-miR-31 is an option for repairing CSD. Our results provide preclinical data supporting the potential application of miRNA gene-modified BMSCs to repair critical-sized calvarial defects.

\section{Acknowledgements}

This work was supported by the National Natural Science Foundation of China $(31271029,81170876$, 21304015, 81070737, 81000404, 81200720, 81100696 and 81320108010), Research Fund for the Doctoral Program of Higher Education of China (20130073110015), the
Shanghai Science and Technology Innovation Project (13JC1403800), and the Shanghai Jiao Tong University School of Medicine Doctor Innovation Fund (BXJ201228).

\section{References}

Al Ruhaimi KA (2001) Bone graft substitutes: a comparative qualitative histologic review of current osteoconductive grafting materials. Int J Oral Maxillofac Implants 16: 105-114.

Aprelikova O, Yu X, Palla J, Wei BR, John S, Yi M, Stephens R, Simpson RM, Risinger JI, Jazaeri A, Niederhuber J (2010) The role of miR-31 and its target gene SATB2 in cancer-associated fibroblasts. Cell Cycle 9: 4387-4398.

Bodakhe S, Verma S, Garkhal K, Samal SK, Sharma SS, Kumar N (2013) Injectable photocrosslinkable nanocomposite based on poly(glycerol sebacate) fumarate and hydroxyapatite: development, biocompatibility and bone regeneration in a rat calvarial bone defect model. Nanomedicine 8: 1777-1795.

Chen Q-Z, Quinn JMW, Thouas GA, Zhou X, Komesaroff PA (2010) Bone-like elastomer-toughened scaffolds with degradability kinetics matching healing rates of injured bone. Adv Eng Mater 12: B642-B648.

Chen Q, Liang S, Thouas GA (2013) Elastomeric biomaterials for tissue engineering. Prog Polym Sci 38: 584-671.

Crapo PM, Gao J, Wang Y (2008) Seamless tubular poly(glycerol sebacate) scaffolds: high-yield fabrication and potential applications. J Biomed Mater Res A 86: 354-363.

Cui L, Liu B, Liu G, Zhang W, Cen L, Sun J, Yin S, Liu W, Cao Y (2007) Repair of cranial bone defects with adipose derived stem cells and coral scaffold in a canine model. Biomaterials 28: 5477-5486.

Deng Y, Wu S, Zhou H, Bi X, Wang Y, Hu Y, Gu P, Fan X (2013a) Effects of a miR-31, Runx2, and Satb2 regulatory loop on the osteogenic differentiation of bone mesenchymal stem cells. Stem Cells Dev 22: 2278-2286.

Deng Y, Zhou H, Zou D, Xie Q, Bi X, Gu P, Fan X (2013b) The role of miR-31-modified adipose tissuederived stem cells in repairing rat critical-sized calvarial defects. Biomaterials 34: 6717-6728.

Ding H, Gao YS, Hu C, Wang Y, Wang CG, Yin JM, Sun Y, Zhang CQ (2013) HIF-1 $\alpha$ transgenic bone marrow cells can promote tissue repair in cases of corticosteroidinduced osteonecrosis of the femoral head in rabbits. Plos One 8: e63628.

Dobreva G, Chahrour M, Dautzenberg M, Chirivella L, Kanzler B, Fariñas I, Karsenty G, Grosschedl R (2006) SATB2 is a multifunctional determinant of craniofacial patterning and osteoblast differentiation. Cell 125: 971986.

Fu H, Rahaman MN, Brown RF, Day DE (2013) Evaluation of bone regeneration in implants composed of hollow HA microspheres loaded with transforming growth factor beta 1 in a rat calvarial defect model. Acta Biomater 9: $5718-5727$. 
Gao J, Crapo PM, Wang Y (2006) Macroporous elastomeric scaffolds with extensive micropores. Tissue Eng 12: 917-925.

Gao J, Ensley AE, Nerem RM, Wang Y (2007) Poly(glycerol sebacate) supports the proliferation and phenotypic protein expression of primary baboon vascular cells. J Biomed Mater Res A 83: 1070-1075.

Handa T, Anada T, Honda Y, Yamazaki H, Kobayashi K, Kanda N, Kamakura S, Echigo S, Suzuki O (2012) The effect of an octacalcium phosphate co-precipitated gelatin composite on the repair of critical-sized rat calvarial defects. Acta Biomater 8: 1190-1200.

Hobert O (2008) Gene regulation by transcription factors and microRNAs. Science 319: 1785-1786.

Kanczler JM, Oreffo RO (2008) Osteogenesis and angiogenesis: the potential for engineering bone. Eur Cell Mater 15: 100-114.

Kharaziha M, Nikkhah M, Shin SR, Annabi N, Masoumi N, Gaharwar AK, Camci-Unal G, Khademhosseini A (2013) PGS:Gelatin nanofibrous scaffolds with tunable mechanical and structural properties for engineering cardiac tissues. Biomaterials 34: 6355-6366.

Kim MJ, Lee B, Yang K, Park J, Jeon S, Um SH, Kim DI, Im SG, Cho SW (2013) BMP-2 peptidefunctionalized nanopatterned substrates for enhanced osteogenic differentiation of human mesenchymal stem cells. Biomaterials 34: 7236-7246.

Lee KW, Johnson NR, Gao J, Wang Y (2013) Human progenitor cell recruitment via SDF-1 $\alpha$ coacervate-laden PGS vascular grafts. Biomaterials 34: 9877-9885.

Li Y, Fan L, Liu S, Liu W, Zhang H, Zhou T, Wu D, Yang P, Shen L, Chen J, Jin Y (2013) The promotion of bone regeneration through positive regulation of angiogenic-osteogenic coupling using microRNA-26a. Biomaterials 34: 5048-5058.

Lin CY, Chang YH, Kao CY, Lu CH, Sung LY, Yen TC, Lin KJ, Hu YC (2012) Augmented healing of criticalsize calvarial defects by baculovirus-engineered MSCs that persistently express growth factors. Biomaterials 33: 3682-3692.

Liu H, Peng H, Wu Y, Zhang C, Cai Y, Xu G, Li Q, Chen X, Ji J, Zhang Y, OuYang HW (2013) The promotion of bone regeneration by nanofibrous hydroxyapatite/chitosan scaffolds by effects on integrin-BMP/Smad signaling pathway in BMSCs. Biomaterials 34: 4404-4417.

Masoumi N, Johnson KL, Howell MC, Engelmayr GC Jr (2013) Valvular interstitial cell seeded poly(glycerol sebacate) scaffolds: toward a biomimetic in vitro model for heart valve tissue engineering. Acta Biomater 9: 59745988.

Mastrogiacomo M, Papadimitropoulos A, Cedola A, Peyrin F, Giannoni P, Pearce SG, Alini M, Giannini C, Guagliardi A, Cancedda R (2007) Engineering of bone using bone marrow stromal cells and a siliconstabilized tricalcium phosphate bioceramic: evidence for a coupling between bone formation and scaffold resorption. Biomaterials 28: 1376-1384.

Mizrahi O, Sheyn D, Tawackoli W, Kallai I, Oh A, Su S, Da X, Zarrini P, Cook-Wiens G, Gazit D, Gazit Z (2013) BMP-6 is more efficient in bone formation than BMP-2 when overexpressed in mesenchymal stem cells. Gene Ther 20: 370-377.

Nguyen LH, Annabi N, Nikkhah M, Bae H, Binan L, Park S, Kang Y, Yang Y, Khademhosseini A (2012) Vascularized bone tissue engineering: approaches for potential improvement. Tissue Eng Part B Rev 18: 363-382.

Pittenger MF, Mackay AM, Beck SC, Jaiswal RK, Douglas R, Mosca JD, Moorman MA, Simonetti DW, Craig S, Marshak DR (1999) Multilineage potential of adult human mesenchymal stem cells. Science 284: 143-147.

Pritchard CD, Arnér KM, Langer RS, Ghosh FK (2010) Retinal transplantation using surface modified poly(glycerol-co-sebacic acid) membranes. Biomaterials 31: 7978-7984.

Rezwan K, Chen QZ, Blaker JJ, Boccaccini AR (2006) Biodegradable and bioactive porous polymer/ inorganic composite scaffolds for bone tissue engineering. Biomaterials 27: 3413-3431.

Schmitz JP, Hollinger JO (1986) The critical size defect as an experimental model for craniomandibulofacial nonunions. Clin Orthop Relat Res 205: 299-308.

Soleimani M, Nadri S (2009) A protocol for isolation and culture of mesenchymal stem cells from mouse bone marrow. Nat Protoc 4: 102-106.

Su Y, Su Q, Liu W, Lim M, Venugopal JR, Mo X, Ramakrishna S, Al-Deyab SS, El-Newehy M (2012) Controlled release of bone morphogenetic protein 2 and dexamethasone loaded in core-shell PLLACL-collagen fibers for use in bone tissue engineering. Acta Biomater 8: 763-771.

Suh JS, Lee JY, Choi YS, Chong PC, Park YJ (2013) Peptide-mediated intracellular delivery of miRNA-29b for osteogenic stem cell differentiation. Biomaterials 34: 4347-4359.

Sundback CA, Shyu JY, Wang Y, Faquin WC, Langer RS, Vacanti JP, Hadlock TA (2005) Biocompatibility analysis of poly(glycerol sebacate) as a nerve guide material. Biomaterials 26: 5454-5464.

Wang Y, Ameer GA, Sheppard BJ, Langer R (2002) A tough biodegradable elastomer. Nat Biotechnol 20: 602606.

Wang Y, Kim YM, Langer R (2003) In vivo degradation characteristics of poly(glycerol sebacate). J Biomed Mater Res A 66: 192-197.

Wu W, Allen R, Gao J, Wang Y (2011) Artificial niche combining elastomeric substrate and platelets guides vascular differentiation of bone marrow mononuclear cells. Tissue Eng Part A 17: 1979-1992.

Xia L, Zhang Z, Chen L, Zhang W, Zeng D, Zhang X, Chang J, Jiang X (2011) Proliferation and osteogenic differentiation of human periodontal ligament cells on akermanite and $\beta$-TCP bioceramics. Eur Cell Mater 22: 68-82.

Xiao W, Fu H, Rahaman MN, Liu Y, Bal BS (2013) Hollow hydroxyapatite microspheres: A novel bioactive and osteoconductive carrier for controlled release of bone morphogenetic protein-2 in bone regeneration. Acta Biomater 9: 8374-8383.

Yan SG, Zhang J, Tu QS, Ye JH, Luo E, Schuler M, Kim MS, Griffin T, Zhao J, Duan XJ, Cochran DJ, Murray 
D, Yang PS, Chen J (2011) Enhanced osseointegration of titanium implant through the local delivery of transcription factor SATB2. Biomaterials 32: 8676-8683.

Yau WW, Rujitanaroj PO, Lam L, Chew SY (2012) Directing stem cell fate by controlled RNA interference. Biomaterials 33: 2608-2628.

Ye JH, Xu YJ, Gao J, Yan SG, Zhao J, Tu Q, Zhang J, Duan XJ, Sommer CA, Mostoslavsky G, Kaplan DL, Wu YN, Zhang CP, Wang L, Chen J (2011) Critical-size calvarial bone defects healing in a mouse model with silk scaffolds and SATB2-modified iPSCs. Biomaterials 32: 5065-5076.

You Z, Bi X, Fan X, Wang Y (2012) A functional polymer designed for bone tissue engineering. Acta Biomater 8: 502-510.

Yuan J, Cui L, Zhang WJ, Liu W, Cao Y (2007) Repair of canine mandibular bone defects with bone marrow stromal cells and porous beta-tricalcium phosphate. Biomaterials 28: 1005-1013.

Zaky SH, Lee KW, Gao J, Jensen A, Close J, Wang Y, Almarza A, Sfeir C (2014) Poly(glycerol sebacate) elastomer, a novel material for mechanically loaded bone regeneration. Tissue Eng Part A 20: 45-53.

Zhang W, Wang X, Wang S, Zhao J, Xu L, Zhu C, Zeng D, Chen J, Zhang Z, Kaplan DL, Jiang X (2011) The use of injectable sonication-induced silk hydrogel for $\operatorname{VEGF}(165)$ and BMP-2 delivery for elevation of the maxillary sinus floor. Biomaterials 32: 9415-9424.

Zou D, Zhang Z, He J, Zhu S, Wang S, Zhang W, Zhou J, Xu Y, Huang Y, Wang Y, Han W, Zhou Y, Wang S, You S, Jiang X, Huang Y (2011a) Repairing critical-sized calvarial defects with BMSCs modified by a constitutively active form of hypoxia-inducible factor-1alpha and a phosphate cement scaffold. Biomaterials 32: 9707-9718.

Zou D, Zhang Z, He J, Zhang K, Ye D, Han W, Zhou J, Wang Y, Li Q, Liu X, Zhang X, Wang S, Hu J, Zhu C, Zhang W, Zhou Y, Fu H, Huang Y, Jiang X (2012) Blood vessel formation in the tissue-engineered bone with the constitutively active form of HIF-1alpha mediated BMSCs. Biomaterials 33: 2097-2108.

\section{Discussion with Reviewers}

Reviewer I: The authors demonstrate that the miRNA gene-modified BMSCs could successfully repair the critical-sized calvarial defects. As both the cultured stem cells and virus mediated gene transfer involved major safety issues, direct targeting the miRNA in the bone microenvironment may be a better choice in clinical translation. See reference by Murata et al. (2013).

Authors: Viral vector-based gene delivery can achieve high transduction efficiency and long-term gene expression, but they may be associated with some shortcomings, such as immunogenicity, carcinogenicity (Wang et al., 2013; Boulaiz et al., 2005). Non-viral approaches show high potential due to advantages of relative safety, ability to transfer large size genes, less toxicity and easiness for preparation etc. However, the clinical application of non-viral methods is still restricted by some limitations, including low transfection efficiency and poor transgene expression (Kodama et al., 2006; Wang et al., 2013; Boulaiz et al., 2005). The safety of a stem cell therapy depends on many factors including the type of cell therapy, the proliferation and differentiation capacity of the cells, the route of administration, the intended clinical location, long term survival of the engraftment, the need for repeated administration, the disease to be treated and the age of the population. Understanding the product profile of the intended therapy is crucial to the development of the nonclinical safety study design (Sharpe et al., 2012; de Sá Silva et al., 2012).

Reviewer II: BMSCs were harvested from young (4 week old) male rats, and implanted into adult (12 week old) animals. Can the authors please comment on why young animal cells were chosen for the treatment, and not from the same age as the operated animals? Also, do you think that the defect healing had a better outcome than there would have been if the adult cells were used?

Authors: BMSCs are valuable in bone tissue engineering and cell therapy, however, the potential of osteogenic differentiation of the cells is critical for the efficacy of therapy. Previous studies (Zhang et al., 2008; Matsubara et al., 2005; Kretlow et al., 2008) showed that the decline in BMSC number and osteogenic differentiation capacity increased with age. In the present study, young (4 week old) male rats, which contain abundant bone marrow along with fragile femurs and tibiae, were used according to previous studies (Zou et al., 2011b; Zou et al., 2012).

\section{Additional References}

Boulaiz H, Marchal JA, Prados J, Melguizo C, Aránega A (2005) Non-viral and viral vectors for gene therapy. Cell Mol Biol 51: 3-22.

de Sá Silva F, Almeida PN, Rettore JV, Maranduba CP, de Souza CM, de Souza GT, Zanette Rde S, Miyagi SP, Santos Mde O, Marques MM, Maranduba CM (2012) Toward personalized cell therapies by using stem cells: seven relevant topics for safety and success in stem cell therapy. J Biomed Biotechnol 2012: 758102.

Kodama K, Katayama Y, Shoji Y, Nakashima H (2006) The features and shortcomings for gene delivery of current non-viral carriers. Curr Med Chem 13: 2155-2161.

Kretlow JD, Jin YQ, Liu W, Zhang WJ, Hong TH, Zhou G, Baggett LS, Mikos AG, Cao Y (2008) Donor age and cell passage affects differentiation potential of murine bone marrow-derived stem cells. BMC Cell Biol 9: 60 .

Matsubara T, Suardita K, Ishii M, Sugiyama M, Igarashi A, Oda R, Nishimura M, Saito M, Nakagawa K, Yamanaka K, Miyazaki K, Shimizu M, Bhawal UK, Tsuji K, Nakamura K, Kato Y (2005) Alveolar bone marrow as a cell source for regenerative medicine: differences between alveolar and iliac bone marrow stromal cells. J Bone Miner Res 20: 399-409.

Murata K, Ito H, Yoshitomi H, Yamamoto K, Fukuda A, Yoshikawa J, Furu M, Ishikawa M, Shibuya H, Matsuda S 
(2013) Inhibition of miR-92a enhances fracture healing via promoting angiogenesis in a model of stabilized fracture in young mice. J Bone Miner Res doi: 10.1002/jbmr.2040.

Sharpe ME, Morton D, Rossi A (2012) Nonclinical safety strategies for stem cell therapies. Toxicol Appl Pharmacol 262: 223-231.

Wang W, Li W, Ma N, Steinhoff G (2013) Non-viral gene delivery methods. Curr Pharm Biotechnol 14: 46-60.

Zhang W, Ou G, Hamrick M, Hill W, Borke J, Wenger K, Chutkan N, Yu J, Mi QS, Isales CM, Shi XM (2008)
Age-related changes in the osteogenic differentiation potential of mouse bone marrow stromal cells. J Bone Miner Res 23: 1118-1128.

Zou D, Zhang Z, Ye D, Tang A, Deng L, Han W, Zhao J, Wang S, Zhang W, Zhu C, Zhou J, He J, Wang Y, Xu F, Huang Y, Jiang X (2011b) Repair of critical-sized rat calvarial defects using genetically engineered bone marrow-derived mesenchymal stem cells overexpressing hypoxia-inducible factor-1 $\alpha$. Stem Cells 29: 1380-1390. 